\title{
REVISED Perceptions of Surrogacy Within the Socio-Cultural
}

\section{Context of Nigeria [version 2; peer review: 3 approved with}

\section{reservations]}

Previously titled: A qualitative investigation of surrogacy as a panacea for infertility in Nigeria

\section{Oluwatobi Joseph Alabi(i)}

Department of Sociology, University of Johannesburg, Johannesburg, Gauteng, 2006, South Africa

V2 First published: 11 Feb 2020, 9:103

https://doi.org/10.12688/f1000research.20999.1

Second version: 24 Sep 2020, 9:103

https://doi.org/10.12688/f1000research.20999.2

Latest published: 08 Feb 2021, 9:103

https://doi.org/10.12688/f1000research.20999.3

\section{Abstract}

Background: Surrogacy might be a reproductive process that brings joy and fulfilment to many, but it also brings with it numerous ethical and legal concerns; it raises questions about the fundamental human rights, welfare and wellbeing of women and infants, especially within a context where it is barely regulated. This article examines the perception of surrogacy within the socio-cultural context of Nigeria. It brings to the fore various socio-cultural concerns that question the influence of surrogacy as a reproductive process on womanhood, motherhood and parenthood. It discusses, by analysing the narratives of the participants, how the surrogacy process is a dereliction of the sacredness and cultural sanctity of the family system, most especially in an African context.

Methods: Fifteen (15) stakeholders (traditional birth attendants, medical gynaecologists and legal professionals within the social, medico-legal framework of reproductive health) in Nigeria were engaged in in-depth interviews to unravel the challenges which surrogacy might be facing or encountering as an ART in Nigeria. Results: There are various social, traditional, cultural, and religious beliefs that police the reproductive sphere of Nigeria, which have grave implications on fertility treatment. These socio-cultural and religious factors do not provide a fertile ground for surrogacy to thrive in Nigeria. Hence, it is important that the socio-cultural framing of reproducing in Nigeria become receptive to modern medical reproductive alternatives and innovations.

Conclusions: For surrogacy to permeate the reproductive terrain of the country there is a need to jettison several socio-cultural and religious sentimental beliefs policing reproduction in Nigeria.

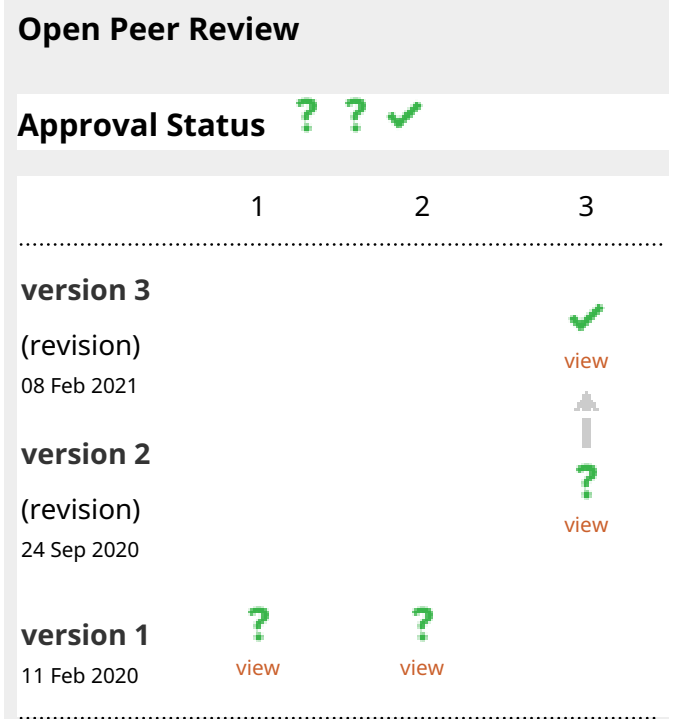

1. Daniela Danna, University of Milan, Milan, Italy

2. George Mbara ID, University of KwaZulu Natal, Durban, South Africa

3. Olufemi A. Fawole ID, University of Ilorin, Ilorin, Nigeria

Any reports and responses or comments on the article can be found at the end of the article. 
Keywords

Surrogacy, reproduction, infertility, culture, religion.

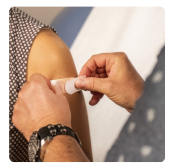

This article is included in the Sociology of

Health gateway.

Corresponding author: Oluwatobi Joseph Alabi (damilarealabi40@yahoo.com)

Author roles: Alabi OJ: Conceptualization, Data Curation, Formal Analysis, Funding Acquisition, Investigation, Methodology, Project Administration, Resources, Writing - Original Draft Preparation, Writing - Review \& Editing

Competing interests: No competing interests were disclosed.

Grant information: The author(s) declared that no grants were involved in supporting this work.

Copyright: @ 2020 Alabi OJ. This is an open access article distributed under the terms of the Creative Commons Attribution License, which permits unrestricted use, distribution, and reproduction in any medium, provided the original work is properly cited.

How to cite this article: Alabi OJ. Perceptions of Surrogacy Within the Socio-Cultural Context of Nigeria [version 2; peer review: 3 approved with reservations] F1000Research 2020, 9:103 https://doi.org/10.12688/f1000research.20999.2

First published: 11 Feb 2020, 9:103 https://doi.org/10.12688/f1000research.20999.1 


\section{REVISED Amendments from Version 1}

This version provides a stimulating and engaging insight into how socio-cultural, religious and legal factors shaping reproduction in South-west Nigeria influence the perception of surrogacy. As an improvement of the former, surrogacy was defined and operationalized as a process of reproduction that involves commissioning pregnancy to another woman and not necessarily a type of Assisted Reproductive Technology. The new version maps out the aim of the study which was to examine the perceptions of surrogacy within the study location. Arguments were presented more critically so the reader can understand how surrogacy within the study location is seen as unpopular and as a process that negates the fundamental cultural and religious medium of reproduction. The influence of surrogacy on the perception of motherhood, reproduction as well as its potential abuse and commercialization of women and babies further expatiated. To appropriately capture the study aim and objectives the title was edited to 'Perceptions of Surrogacy Within the Socio-cultural Context of Nigeria.' Also, a thorough language and syntax editing was carried out on the previous version to produce an easier to read version. Most of the changes made to the style of presenting arguments in this paper were in line with reviewers' suggestions. I hope you find this version more informative and critically engaging.

\section{Any further responses from the reviewers can be found at} the end of the article

\section{Introduction}

Infertility is described as a global public health challenge affecting between 13-17 per cent of couples trying to conceive in sub-Saharan Africa, with a higher rate of about 32 per cent in most of the countries sampled in the survey; this is according to the infertility survey conducted in 27 sub-Saharan countries including Nigeria. As the percentage of infertility remains high in most countries in sub-Saharan Africa $(32 \%)$, the pressure on couples to procreate and find solutions to their stigmatised status becomes extremely complex. Infertility across most parts of Africa has not been well researched as a vital part of sexual reproductive health, yet its impact can be highly consequential ${ }^{1}$. Having biological children is highly desirable and the inability to conceive is often demonised, socially stigmatised, and often leads to divorce or results in adverse psychological and health effects on the partners involved ${ }^{2}$. It is also important to understand the gender narratives around infertility in most parts of sub-Saharan Africa; while men and women can both be potentially infertile, women are often blamed and punished for childlessness ${ }^{3,4}$. Within this immensely complex socio-cultural milieu that prioritises fertility and links procreation to the completeness of a man or woman, couples are put under pressure to bear children and failing to do so is regarded as an existential failure. Studies show that the pressure to have children has increased risky sexual behaviour among couples in sub-Saharan Africa ${ }^{4}$.

The search for infertility treatment is a complex terrain to navigate because infertility possesses socio-cultural attributes and challenges at both foundational and experimental levels? Explanations of the aetiology of infertility differ between healthcare providers, patients and the society in Nigeria ${ }^{7}$. Western medicine can diagnose infertility biologically and administer clinical recommendations; however, indigenous medicine believes that factors causing infertility could be biological or even supernatural ${ }^{7}$. This dichotomy in the aetiology of sickness in general and infertility, in particular across Africa, is foundational for the various socio-cultural narratives surrounding reproduction and its alternatives in Nigeria. There are various socio-cultural beliefs policing fertility in Nigeria and these beliefs are of grave concern due to the perception of and attitude towards infertility ${ }^{2}$. The cultural environment is paternalistic and as such, children are highly desired, and parenthood is culturally mandatory ${ }^{2}$. Any standard below this paternalistic cultural expectation is regarded as cultural deviation and often stigmatised ${ }^{2}$.

The challenge of infertility in sub-Saharan Africa is debated among researchers, especially because of the complex sociocultural narratives surrounding reproduction in the region. As such, various treatment alternatives have been debated and discussed in the literature. Over the years, adoption has been one of the most popular routes taken by couples in Nigeria struggling with bearing children ${ }^{8}$, however, as practices such as surrogacy become more globally popular, it is important to understand the perceptions and its dynamics in Nigeria. Notwithstanding the popularity of adoption, it is a very challenging and complex process to embrace in Nigeria as a result of various stigma and stereotypes ${ }^{9}$. A previous study among the Yoruba people of Western Nigeria revealed that the acceptability of child adoption has several socio-cultural factors that influence the success, some of which include a lack of adequate information about the adoption process ${ }^{10}$. These limitations have also been discussed as prominent in Eastern Nigeria $^{11}$. These socio-cultural challenges are not particular to the South-West or Eastern parts of Nigeria alone, as it is important to note that despite the heterogeneous nature of the Nigerian society, a common narrative across these cultures is the premium placed on children, emphasis on parenthood, and the norm that every woman should conceive and carry children to term ${ }^{2}$. Implicatively, fertility is highly valued across genders and is often seen as a validation of womanhood or manhood.

Surrogacy is a process whereby a third party (woman) of childbearing age carries a pregnancy for a commissioning parent with the intention of relinquishing the baby after birth, usually enforced by a contractual agreement between the parties involved ${ }^{16}$. The United Nations Special Rapporteur defined surrogacy as "a form of third-party reproductive practice in which intending parents(s) contracts a surrogate mother to give birth to a child ${ }^{35}$." While the birth of baby Louise Brown in 1978 (the first baby conceived through in vitro fertilisation in England) rekindled the hope of many childless couples across the world on the possibility of having children that are genetically connected to them ${ }^{12}$, it must be noted that surrogacy is not necessarily a type of ART but rather a reproductive process that relies on another person (a woman) to carry a child to term. ART has become very popular for treating infertility the world over, but with impeding 
challenges especially in developing nations. Assisted Reproductive Technology (ART) in general is basseted with numerous challenges in Nigeria and these include, availability of limited reproductive centres; highly priced charges to seek reproductive help as most of the reproductive centres are operated by private organisations that are profit driven ${ }^{13}$; and, low success rates ${ }^{10}$. Even though there are many options for infertility treatment across the globe, the success of such processes depend on etiological factors, availability of medically advanced diagnostic tools, skills of the attending physician and financial status of the couples involved ${ }^{14,15}$. This study recognises and expands on the various challenges debated in literature in Nigeria and furthers the conversations around other fertility treatments in Nigeria, particularly surrogacy.

Surrogacy as a reproductive process is swamped with numerous challenges spanning through parental rights, the fundamental human rights of the child, and women abuse, specifically the exploitation of surrogate mothers, among others. The legal, ethical, and socio-cultural trepidations debated in the practice of surrogacy remains germane in literature. Some of the concerns that have gained popular attention includes that it is imperative to ensure that the rights of the child are not abused irrespective of the terms of the contract/agreement between parties; and, that the idea that the woman's body could be perceived as just a medium for reproduction or commercialised without recourse to her emotions or the possibility of bonding with the baby through the period of gestation is abusive and must be addressed. As medical tourism becomes expansive and inter-country gestational surrogacy driven by monetary incentives more popular, the fear of exploitation, conflicting legislation and loss of autonomy have become highly debated in medicolegal and bioethical spheres. It becomes even more complex in a country like Nigeria where there is no clear-cut legislation for surrogacy. This has created many loopholes within the reproductive space of the country with practices like 'baby factories' thriving as illicit fertility clinics while actually exposing babies and women to abuse and exploitation. This study discusses surrogacy within a socio-cultural context in Nigeria. It brings to the fore the various narratives and perceptions of surrogacy by engaging gynaecologists, legal professionals, and traditional birth attendants through interviews.

\section{Methods}

Study design

This research is qualitative, and its strategy of inquiry is explorative. In utilising this exploratory approach, the researcher, through painstaking interviews, accessed the perceptions of gynaecologists, traditional birth attendants (TBA) and legal professionals on the practice of surrogacy in Nigeria. Exploratory qualitative research allows the researcher to collect data from persons who possess relevant knowledge about a phenomenon and assists in developing a composite description of the essence of their experience for all individuals ${ }^{17}$.

\section{Ethical considerations}

This study was approved by the University of KwaZulu-Natal ethical clearance Committee (Protocol number: HSS/0705/017M) after due consultation and the gatekeepers' consent letters were provided by Ekiti State Teaching Hospital, Ado-Ekiti, EkitiState and Oyedeji Ayodele and Co, Abuja Nigeria.

\section{Participants}

The study population consisted of three categories of participants. These included ten gynaecologists, five TBAs and five legal professionals. This study was conducted in two cities in Nigeria: the gynaecologists and TBAs were recruited and interviewed at Ekiti State Teaching Hospital, Ado-Ekiti, Ekiti State Nigeria; and the legal professionals were recruited and interviewed at Oyedeji Ayodele and Co, Abuja, Nigeria.

Considering that surrogacy is not a popular practice in Nigeria, purposive sampling was used to select participants. Both institutions served as a welcoming host to the researcher and provided access to participants and premises. The Ekiti State Teaching Hospital in Ado-Ekiti is one of the foremost fertility clinics in the South-western part of the country and thus a suitable location for the study; while, Oyedeji Ayodele legal chamber is one that has handled many legal disputes regarding children, paternity and reproductive contracts over the years. Both locations had the criteria to provide the required information this study needed.

Informed consent was gained by detailing the purpose of the study and the strategies to ensure the participants' anonymity and confidentiality were explained to them before the study began, where after they voluntarily signed the consent forms. The informed consent included that the participants could withdraw from the study at any point if they no longer feel comfortable.

\section{Sampling}

Purposive sampling was adopted to recruit participants in the study. The institutions that served as a host for the researcher provided access to legal professionals, gynaecologist and TBA's. Upon receiving ethical clearance from the University of KwaZulu-Natal, the gynaecological centre of Ado Ekiti Teaching Hospital was visited, and appointments were made to interview gynaecologists at their convenience. The department also served as a link to the association of TBAs in Ekiti State. Oyedeji Ayodele and Co. was also visited in Abuja where interested legal professionals within the chamber were approached and interviewed.

\section{Data collection}

Face-to-face in-depth interviews were conducted with each participant using a semi-structured interview schedule that contained three sets of questions. An audio recorder and field notes were used to collect the data. The participants had consented to the recording of the interview with an audio recorder on their informed consent form. The first set of questions examined surrogacy within a cultural perspective, the second questioned medical opinions on surrogacy arrangements as it pertains to Nigeria, and the third examined the legal trepidations in the practice of surrogacy. The interview schedule was translated into Yoruba, the most commonly spoken language in Ekiti State, for the benefit of the TBAs who might 
not be English speakers. Interviews lasted on average of 30-70 minutes.

Not all the participants approached participated in the study. Considering the nature of the medical and legal profession, the timing was a major constraint; several of the legal practitioners and gynaecologists cancelled appointments more than twice, and some were finally not interviewed. However, data saturation was a major guide during the process of the fieldwork. The narratives from participants were constantly assessed to identify when new information was derived, and when there were very frequent repetitions data saturation was reached and the fieldwork came to an end.

Audiotapes were transcribed by the researcher and interview transcripts and summaries were checked with participants to ensure that their narratives were captured correctly and not distorted in any way.

\section{Data analysis}

Thematic content analysis was adopted to analyse the field notes and transcripts. Thematic content analysis is an approach to the analysis of documents and texts (which may be printed or visual) that seeks to quantify content in terms of predetermined categories (in this research emerging categories from participants' narratives) in a systematic and replicable manner ${ }^{18}$. Transcripts from the interviews were organised into a logically readable format, after which recurrent patterns and conceptual issues were identified and developed into themes that formed the basis for the analysis. Participant numbers and characteristics (age, gender, and job) (see Table 1) were used in reporting the findings of this study to ensure the anonymity of participants as noted in the informed consent.

\section{Results}

The dynamic nature of human societies coupled with varying regulatory normative codes across cultural boundaries creates the need to examine the perception of surrogacy within various cultural settings in order to appreciate its dynamic and contextual peculiarities. The imperative questions that steered this study included a need to understand how surrogacy is conceptualised in Nigeria; and a concern to understand the socio-cultural imperatives influencing/shaping the practice in Nigeria. The themes discussed include the social perception of surrogacy; the socio-cultural intricacies of surrogacy and its implication for the normative understanding of a 'woman'; the gendered nature of infertility and, the effect of surrogacy on the structure of parenthood.

\section{Social perception of surrogacy in Nigeria}

The participants provided varying thoughts on the popularity of surrogacy in Nigeria. Some of these seemed to be influenced by personal beliefs, religious and cultural sentiments, as well as knowledge about the practice. A careful examination of the responses revealed complex narratives that further strengthens the debates in literatures that surrogacy brings to the fore various legal, socio-cultural, and ethical concerns. Most of the gynaecologists and legal professionals expressed support for

\section{Table 1. Demographic characteristics of participants.}

\begin{tabular}{|l|l|l|}
\hline \multicolumn{3}{|l|}{ Gynaecologists } \\
\hline s/n & Gender & Age \\
\hline 1 & Male & 37 \\
\hline 2 & Male & 46 \\
\hline 3 & Male & 36 \\
\hline 4 & Male & 39 \\
\hline 5 & Male & 45 \\
\hline 6 & Male & 39 \\
\hline 7 & Male & Adult \\
\hline 8 & Male & 38 \\
\hline 9 & Male & 40 \\
\hline 10 & Male & 48 \\
\hline Legal professionals \\
\hline 11 & Male & 34 \\
\hline 12 & Male & 34 \\
\hline 13 & Male & Adult \\
\hline 14 & Female & Adult \\
\hline 15 & Female & Adult \\
\hline Traditional birth & \\
\hline attendants & Female & 65 \\
\hline 16 & Female & 49 \\
\hline 17 & Female & 58 \\
\hline 19 & Female & 40 \\
\hline 20 & Female & 53 \\
\hline
\end{tabular}

the practice of surrogacy even though they noted that it is a complex terrain to navigate, while TBAs believe it is a practice that negates normative reproductive processes and a concept that could commercialise babies and the woman's body. Most TBAs strongly drew on religious and cultural beliefs in their discussion of surrogacy as a reproductive process. One of the gynaecologists mentioned that:

Surrogacy in Nigeria is not a popular practice, it is not that popular because when viewed from a socio-cultural lens, there are lots of beliefs, controversies that surround surrogacy. In most quarters in Nigeria, surrogacy is not popular at all and I will say the popularity and acceptance of the practice are hugely influenced by socio-cultural, legal, and spiritual factors. The legal space has not created platforms that support or regulate the process and the socio-cultural and religious aspects of our society are not in favour of such acts that distort natural order (Gynaecologist, $M, 48$ years). 
All the gynaecologists interviewed believe that surrogacy will gain prominence with time and as the country continues to transform; however, they also believe that it is still in its infancy and essentially still unpopular. They also emphasised that the popularity of the process is hampered by socio-cultural beliefs and values regulating reproduction. Notwithstanding, they noted that surrogacy is becoming a thriving venture in major urban settlements like Abuja, Lagos, and Port-Harcourt, even though the legal terrain in which it operates remains unregulated.

The legal professionals interviewed believed surrogacy is a controversial, non-existent and with a very low patronage in Nigeria.

The opinions shared by TBAs elaborated on the religious and socio-cultural factors influencing the popularity of surrogacy in Nigeria discussed in the previous section:

Our prayer is that this act won't gain prevalence and acceptance in Nigeria, because it is anti-cultural and anti-religion. God has established a process for that and no one or advancement should change it. It is a devilish act championed by the western world and it won't succeed in our land. How do you expect a woman that did not gestate a child to know the real worth and value of that child? Or how does the child become a true member of the kin when another woman gestated him/her. God forbid, it won't work here. I have heard people are doing it already, but God will destroy their plans (TBA, F, 58 years).

All the TBAs shared the same opinion that surrogacy is becoming a social discussion in Nigeria; however, they hoped it would not thrive within the country because it goes against cultural and religious norms for reproduction. The reservations they have for the practice include the fact that the surrogacy process will destroy the entire process of normal reproduction- which spans through the period of pregnancy, bonding, as well as the premium placed on children. The terrain of surrogacy is indeed very complex and currently does not constitute an important aspect of public discussion ${ }^{19,20}$. What surrogacy means and the social reception it enjoys differ across cultural and social boundaries. It is quite evident from participants' narratives that the discussion of surrogacy brings to the fore several concerns that are often influenced by the social, cultural and religious beliefs of the community ${ }^{21}$.

Surrogacy and its practice is borne out of a desire to have a child $^{22}$, and contemporary practice thereof is often hinged on a desire to have a child with a biological connection ${ }^{23,24}$. Moreover, the process as discussed is complex and could potentially lead to the exploitation and abuse of fundamental human rights, hence it remains a highly debatable topic. For instance, perceptions of surrogacy may also be grounded in descriptions that suggest commercialisation and exploitation of women ${ }^{25,26}$. Commercialising a woman's body by renting her womb and putting a price tag on the children that is a product of this process is highly dehumanising and disregards a fundamental human right.
TBAs in this research described surrogacy as an act that distorts the cultural normative process for reproduction and disregards the role of women. Surrogacy in Yoruba language is translated as "agbabi odi omo eni", meaning "contracted pregnancy does not become yours'. The meaning and definition of the process in this local language suggests a difference between the surrogate and child, as well as between the commissioning parent and the child, and that in itself is reinforcing the stigma placed on infertility. Hence, surrogacy is perceived as a way of expressing how one woman was unsuccessful in conceiving a child; this role, however, has been taken up by another woman who has the physiological capability to conceive and carry a child to term, without paying attention to the possible feelings that might be involved as the surrogate mother carries the child to term. The process also fragments parenthood and raises serious paternity issues according to these traditional birth attendants. These narratives by TBAs describe surrogacy as a deviating act and even in cases of altruism, the altruism of the surrogate is regarded as ranging beyond normative boundaries ${ }^{27}$. The perceptions of surrogacy among this study's participants highlights the complexities and multiple contestations that characterises the entire process. Some of the socio-cultural, religious and ethical trepidations mentioned in this sections will be discussed further.

\section{Fragmenting womanhood: socio-cultural intricacies in the process of surrogacy and the understanding of a 'woman'}

Across most African societies, there is a great deal of significance placed upon a woman . They play a significant role in the continuity of the community and the operation of social life and are considered the fabricators of life and the mothers of humankind. As a major player in the personal rituals associated with birth, puberty, and death, the symbolism of these rituals demonstrates the important cultural meanings of womanhood $^{28}$. There is a connection between fertility, culture, and religion across most African cultures ${ }^{29}$. While the ability to conceive and carry a child to term is regarded as a gift and partly the workings of a supernatural being, the cultural definition of a woman is her ability to perform the gestational role of carrying a child to term. Across most of African cultures, high fertility is not only a divine reward but evidence of the right behaviour. Among the Chaga of Tanzania, the wife in complying with the divine order has been described in these words: "she corporates with her husband, the ancestors, even God, in creating the child" ${ }^{30}$. Hence, it can be inferred that fertility is a product of complete obedience to God and the ancestors, and exuding what is considered conforming behaviours. Children are highly desired, and women are accorded a lot of regard for being fertile, usually adjudged on their ability to conceive, carry to term and nurture a child. The birth of a child is celebrated and seen as a sign of divine approval by both living and dead/ancestors. However, infertility is regarded most times as a woman's problem and evidence of $\sin$ and disapproval by both God and the ancestors ${ }^{30}$. These are extraordinarily strong gendered assumptions that continue to domesticate women, sexualise their bodies, and produces female oppression within the study's location. 
The perceptions shared by the participants are diverse but entrenches the notion that fertility and children are important parts of the African community. A woman's ability to conceive and carry a child to term defines her and serves as a rite of passage to womanhood. In addition, religion is fundamental to the conception of fertility, while infertility is an aberration that probably results from sin. Notwithstanding, surrogacy is not seen as a solution to infertility but rather as a further disregard for religion and culture. TBAs believe that an infertile couple must continue to pray and seek alternatives that will not be unnatural. When most of the participants were asked about how they think the practice of surrogacy will influence the conceptualisation of womanhood, various issues emerged, including:

Personally, it is against the definition of womanhood and even the surrogate is not thoughtful enough, what will the surrogate tell her own husband after she must have done something like this. Will she say she has not given birth before or what? What if she cannot give birth again? Even if she marries and now have a child through the cultural medium with her husband, would she now refer to this present child as her first seed or the surrogate child? This is disturbing, confusing and against our culture (TBA, F, 53).

The notion that surrogacy is a reproductive process that encroaches on the pertinent understanding of reproduction and womanhood was shared by all TBAs and in fact they believe that it is not a practice any of the parties involved will be proud to identify with. In addition, surrogacy was seen as a negation of the acceptable religious process for reproduction:

God created the man and woman. There is a plan and process designed by the creator for procreation. God endowed women for reproduction, and he did not sanction surrogacy or at least my own religion does not teach me to do that. The Bible says there shall be non-barren in the land. That there will be children in your loins, so it does affect the definition of womanhood and the whole commandment of being fruitful (TBA, F, 40 years).

The responses captured above further reiterate the intersection between religion and culture in the perception of fertility and procreation within this context and across most African cultures. It is an intersection that evidently shapes the perception of surrogacy in Nigeria. While these beliefs are arguably producing assumptions that seek to police women's sexuality and reproductive abilities, it does raise fundamental questions about the legality and ethicality of surrogacy and how it affects women and children.

\section{Gendering infertility: women's infertility as a consequence of promiscuity and recklessness}

The perception that infertility is regarded as evidence of sin or recklessness was discussed by participants. For example, it was noted that infertility may be the result of the reckless lifestyle the woman may have lived as a youth:

We cannot change the gender of the woman because she can't carry a child, but it must be that the woman that requires the service of a surrogate must have lived a reckless life as a youth, maybe she must have aborted three to four times before marriage. So, she will later have problems with giving birth, but the husband won't know. So, she's still a woman that has no experience or knowledge of what it means to be pregnant and carry the baby to full term. Most times these couples struggling to give birth, especially the women have been promiscuous and reckless, so she's reaping the fruit of her labour. Instead of going through this ungodly medium, she must cry unto God and ask for forgiveness. It is only God that can give children (TBA, $F, 65$ years).

The perception that infertility is a punishment for a perceived sin or recklessness usually associated with women was quite resounding. The gendered nature of infertility is actually an idea that some participants noted to have shaped the perception of fertility in Nigeria:

Childlessness is a taboo, a curse and seen as the woman's fault mostly. Even our doctors stereotypical and superstitious perception of the causes of infertility is absolutely amazing. I was surprised when a doctor said, childlessness is 30 per cent the woman's fault, 30 per cent the man's fault and 40 per cent unknown causes. But up until now the way it is treated is as if when you are childless it is the woman's fault (Legal professional, $F$, adult).

The gendered nature of infertility from the response above is quite popular in Nigeria and cuts across class. Equating a woman's ability to birth a child to her attainment of womanhood is also a common narrative that further stigmatises women. One of the participants noted that:

Womanhood within our culture is defined in terms of a woman's ability to get pregnant and carry a child to term. So, a woman that adopts the option of surrogacy will not have an opportunity of giving birth by herself and that will question her womanhood, a lot of people will see her as not being woman enough because she has not been seen to be pregnant. People attach being able to get pregnant as a mark of womanhood, so surrogacy will affect womanhood negatively, especially where people place a lot of emphasis on a woman's ability to get pregnant, gestate and carry the child to term (Gynaecologist, M, 45 years).

These narratives suggest that without gestating and carrying a foetus to term, it is culturally believed that the woman is incomplete and has failed in her role, and as such transferred this responsibility to another. 'Renting' a womb for surrogacy, as discussed in the literature ${ }^{31,32}$, is seen in this context as a cultural anomaly and misnomer. A process that fragments womanhood and commercialises reproduction:

It really doesn't influence it except to prove that one woman failed, and another woman is doing her work for her. In the sense that we have linked womanhood especially in Africa to motherhood, the ability to conceive and birth a child. That's what we call a complete woman, the average woman wants to be a mother so when there's a woman 
that can't give birth, we might want to re-evaluate what womanhood means. It also means that society is evolving and when things are not the way they should be 100 per cent we have found ways of bridging the gap (Legal professional, $M$, adult).

The participant above noted that the failure of a woman to fulfil her cultural role as a woman has essentially created a gap that another women will fill, either for altruistic reasons, e.g. helping the woman fulfil her social expectations of becoming a mother, or for financial gain inherent in the practice of commercial surrogacy. This legal professional is of the opinion that surrogacy as it is practiced is new to Nigeria but might start to become entrenched basically because of the premium placed on having children. One participant stated that while the practice negates the normative ways of procreation, it also fulfils a cultural goal of helping other infertile couples build a family:

In my own view, how it affects the definition of womanhood is; it depends on how you look at it, especially in an African setting where it is believed that if a woman does not bear a child then the woman is not fulfilled. Interestingly, now we have women coming out to help women in the actualisation of their desire to have a baby, so I think this has really gone a long way and has put a smile on the faces of lots of females around the world and it as really makes womanhood more appreciated than what you can ever think of (Gynaecologist, M, 39 years).

Another participant believes that surrogacy provides a positive view for arguments that parenthood is not just biological but could be social or by assuming the responsibility of raising another person's child. One of the participants noted that:

Surrogacy redefines the whole essence of the family and parenthood. It makes us think of a woman beyond just bearing children. It reminds us there is more to a woman than just bearing children because at the end of the day even if there is a problem with the man, everybody stigmatises the woman in a childless union. It means a woman can be a woman without necessarily bearing a child (Legal professional, $M, 34$ years).

Further reiterating this line of thought, another participant noted that:

Hmmm.... Well the definition of womanhood generally around here is complex because in the real sense being a mother is not about giving birth like we also say being a father is not about fathering a child, but the roles and responsibilities assumed. However, we find out that being a woman has been defined with being able to conceive in the African sense, so surrogacy thus affects this definition of womanhood. Not being able to conceive is more or less like you are less than a woman, in fact, I have seen where people have written that if you give birth through caesarean operation (CS) then you are not a true woman. So, I can imagine that in that circle giving birth through a surrogate tampers with the traditional definition of womanhood, however, the world is evolving and people are defining motherhood and fatherhood by roles and responsibilities assumed in the life of a child (Legal professional, $F$, adult.)

This participants discussed surrogacy from a very positive point of view by focussing on the fact that it helps individuals fulfil the normative social expectations of raising a family where children are regarded as a premium, but it has failed to bring into context the exploitation, complexities in parentage and other ethical issues inherent in the practice. The conflict between agency and protecting the rights of the child that will be a product of this process, as well as some of the women who are often caught in a complex web of unequal power relations, makes the terrain very complicated to navigate. It also reemphasises the need for a comprehensive reproductive legislation in Nigeria that will protect women and children from all forms of exploitation and abuse.

\section{Discussion}

This study brings to the fore sacrosanct socio-cultural, religious, ethical and legal musings influencing the perception of surrogacy in Nigeria. The study revealed that even though surrogacy appears to be practiced in Nigeria, it is hidden and unpopular. While surrogacy might be glorious news for couples struggling to have children where natural conception is impossible, it is raises various concerns because of its potential to exploit women, commercialise their bodies and disregard the fundamental rights that should protect the child ${ }^{20}$.

Some of the socio-cultural factors strongly influencing the perception of surrogacy includes the gendered nature of infertility where women are often seen as problematic partners when couples are struggling to conceive. This perception is accompanied by various stigmas that label, diminish and only recognise the reproductive abilities of women. For example, in the present study, the ability of a woman to gestate is attached to her completeness or her attainment of womanhood, because when she fails to fulfil this social expectation, she becomes stigmatised and considered less a woman. This attitude will discourage women from seeking fertility treatment and may lead to couples with fertility challenges becoming secretive about their medical concerns. Another stigma associated with infertility is that women having challenges conceiving are believed to have been promiscuous and reckless in their youth. It is important to challenge gendered notions of infertility because it is evident from the narratives shared by participants that when issues of infertility are discussed, women often occupy the centre of the discussion and very little is discussed regarding male infertility. Most of the participants believe that surrogacy is a process that distorts normative socio-cultural definitions of a woman, and commercialises children and the entire process of reproduction. Notwithstanding some other participants are of the opinion that it helps infertile couples achieve their aim of raising a family with the help of another - a surrogate. 
The findings of this study were limited by time and resources. The focus was on one of the fertility clinics at the Ekiti-State Teaching Hospital, and as such does not provide sufficient data for generalising the findings. However, it provides a detailed empirical framework for examining the common perception about surrogacy in Nigeria.

\section{Conclusions}

This study has unpacked the various socio-cultural and religious trepidations in the practice of surrogacy in Nigeria. Through painstaking interviews with gynaecologists, legal practitioners and traditional birth attendants, the study unravelled that there are several socio-cultural and religious factors policing the reproductive sphere in Nigeria that makes it difficult for surrogacy to thrive. The overarching influence of socio-cultural beliefs on issues like infertility makes it extremely difficult for processes like surrogacy, considered unnatural, to thrive. Some of the essential findings from this study include that infertility is highly gendered and women often occupy the centre of discussions around infertility. It became evident from the findings that there is a socio-cultural as well as a religious lens through which women are viewed, and this lens does not condone surrogacy. Some of the crucial factors referenced while explaining what it means to be a woman include gestation and carrying a child to term. It is believed that the period of gestation builds a special bond between the woman and the child, and this is important for kinship formation. Interestingly, the lack of specific legislations regulating surrogacy in Nigeria makes the process uniquely challenging and exposes women and infants to potential abuse and exploitation. This legislative lacuna has also fuelled the illicit trade of baby factories that have become quite popular in Nigeria. While the socio-cultural space in the country does not give an enabling environment for surrogacy to thrive, the premium placed on fertility and bearing children provides an indirect demand for illicit baby factories to continue to grow. There is a need for an attitudinal change in the perception of infertility in Nigeria to reduce stigma and discrimination. Legislative gap in Nigeria has played significant role in the growth of baby factories, hence, the abuse and exploitation of women and babies. As such, it is important to effectively legislate surrogacy and provide a broad legislative framework for reproduction so as to protect women, children and babies from abuse, exploitation and commercialization.

\section{Data availability}

Underlying data

Figshare: Surrogacy Transcript. figshare. Dataset. https://doi. org/10.6084/m9.figshare.11120891.v133.

Data are available under the terms of the Creative Commons Attribution 4.0 International license (CC-BY 4.0).

\section{Extended data}

Figshare: Interview schedule, https://doi.org/10.6084/ m9.figshare.10264904.v1 $1^{34}$.

Data are available under the terms of the Creative Commons Zero "No rights reserved" data waiver (CC0 1.0 Public domain dedication).

\section{Acknowledgements}

I wish to acknowledge my appreciation to Dr Mariam SeedatKhan who supervised my master's research, she gave me the right impetus and guidance to investigate an area of research that is seemingly grey and unexplored. I am also grateful to Dr Babatunde Olofinbiyi and $\mathrm{Mr}$ Sunday of Ekiti-State Teaching Hospital Ado-Ekiti for their support in the data collection process. Miss Damilola Oginni and Miss Gbemisola Oginni were also very crucial in the success of my fieldwork.
1. Polis $\mathrm{CB}$, Cox $\mathrm{CM}$, Tunçalp Ö, et al.: Estimating infertility prevalence in low-tomiddle-income countries: an application of a current duration approach to Demographic and Health Survey data. Hum Reprod. 2017; 32(5): 1064-1074. PubMed Abstract | Publisher Full Text | Free Full Text

2. Alabi OJ: Socioeconomic Dynamism and the Growth of Baby Factories in Nigeria. SAGE Open. 2018; 8(2): 2158244018779115. Publisher Full Text

3. Cui W: Mother or nothing: the agony of infertility. Bull World Health Organ 2010; 88(12): 881-2.

PubMed Abstract | Publisher Full Text | Free Full Text

4. Dhont N, van de Wijgert J, Coene G, et al.: 'Mama and papa nothing': living with infertility among an urban population in Kigali, Rwanda. Hum Reprod. 2011; 26(3): 623-629.

PubMed Abstract | Publisher Full Text

5. Asemota OA, Klatsky P: Access to infertility care in the developing world: the family promotion gap. Semin Reprod Med. Thieme Medical Publishers. 2015; 33(1): 17-22.

PubMed Abstract | Publisher Full Text

6. Okonofua F, Menakaya U, Onemu SO, et al.: A case-control study of risk factors for male infertility in Nigeria. Asian J Androl. 2005; 7(4): 351-361. PubMed Abstract | Publisher Full Text

7. Fehintola AO, Fehintola FO, Ogunlaja OA, et al:: Social Meaning and Consequences of Infertility in Ogbomoso, Nigeria. Sudan Journal of Medical Sciences. 2017; 12(2): 63-77.

Publisher Full Text

8. Omosun $\mathrm{AO}$, Kofoworola O: Knowledge, attitude and practice towards child adoption amongst women attending infertility clinics in Lagos State, Nigeria. Afr J Prim Health Care Fam Med. 2011; 3(1): 259. Publisher Full Text | Free Full Text

9. Nwaoga CTN: Socio-religious implications of child adoption in Igboland South Eastern Nigeria. Mediterr J Soc Sci. 2013; 2(11): 705 Publisher Full Text

10. Oladokun A, Arulogun O, Oladokun R, et al.: Acceptability of child adoption as management option for infertility in Nigeria: evidence from focus group discussions. AfrJ Reprod Health. 2009; 13(1): 79-91. PubMed Abstract

11. Omeire CO, Iheriohanma EBJ, Osita-Njoku A, et al.: The challenges of child adoption and the emergence of baby factory in South Eastern Nigeria. 
Int J Educ Res. 2015; 3(8): 63-74.

Reference Source

12. Steptoe PC, Edwards RG: Birth after the reimplantation of a human embryo. Lancet. 1978; 2(8085): 366.

PubMed Abstract | Publisher Full Text

13. Giwa-Osagie OF: The need for infertility services in the developing world: the WHO point of view. Gynecol Obstet Invest. 2004; 57(1): 58. PubMed Abstract

14. Okonofua FE: Infertility in sub-Saharan Africa. Contemporary Obstetrics and Gynaecology for Developing Countries. 2003; 8: 128-56.

15. Okunlola MA, Adebayo OJ, Odukogbe AA, et al.: Assessment of tubal factor contribution to female infertility in a low resource setting (southwest Nigeria): hysterosalpingography vs laparoscopy. J Obstet Gynaecol. 2005; 25(8): 803-804.

PubMed Abstract | Publisher Full Text

16. Banerjee S, Basu S: Rent a womb: Surrogate selection, investment incentives and contracting. J Econ Behav Organ. 2009; 69(3): 260-273. Publisher Full Text

17. Creswell JW: Standards of validation and evaluation. Qualitative inquiry and research design: choosing among five approaches. 2013; 2: 201-21. Reference Source

18. Bryman A: Social research methods. Oxford university press. 2016. Reference Source

19. Bello FA, Akinajo OR, Olayemi O: In-vitro fertilization, gamete donation and surrogacy: Perceptions of women attending an infertility clinic in Ibadan, Nigeria. Afr J Reprod Health. 2014; 18(2): 127-133. PubMed Abstract

20. Umeora OUJ, Umeora MC, Emma-Echiegu NB, et al.: Surrogacy in Nigeria: Legal, ethical, socio cultural, psychological and religious musings. Afr J Med Health Sci. 2014; 13(2): 105-109. Publisher Full Text

21. Armour KL: An overview of surrogacy around the world: trends, questions and ethical issues. Nurs Womens Health. 2012; 16(3): 231-236. PubMed Abstract | Publisher Full Text

22. Danna D: Contract Children: Questioning Surrogacy. ibidem-Verlag/ibidem Press. 2015.

Reference Source

23. Deomampo D: Defining parents, making citizens: nationality and citizenship in transnational surrogacy. Med Anthropol. 2015; 34(3): 210-225. PubMed Abstract | Publisher Full Text

24. Melhuus M, Syse A: Gestational Surrogacy in Norway. Handbook of Gestational Surrogacy: International Clinical Practice and Policy Issues. 2016; 217. Publisher Full Text

25. Chatterjee P: Human Trafficking and Commercialization of Surrogacy in India. European researcher. Series A. 2014; 85(10-2): 1835-1842.

Publisher Full Text

26. White PM: Commercialization, Altruism, Clinical Practice: Seeking Explanation for Similarities and Differences in Californian and Canadian Gestational Surrogacy Outcomes. Womens Health Issues. 2018; 28(3): 239-250. PubMed Abstract | Publisher Full Text

27. Teman E: The social construction of surrogacy research: an anthropological critique of the psychosocial scholarship on surrogate motherhood. Soc Sci Med. 2008; 67(7): 1104-1112. Med. 2008; 67(7): 1104-1112.
PubMed Abstract | Publisher Full Text

28. Nhlekisana RO: From Childhood to Womanhood: Puberty Rites of! Xoo Girls of Zutshwa. Marang: Journal of Language and Literature. 2017; 29: 31-41. Reference Source

29. Fernandez R, Alessandra F: Culture: An empirical investigation of beliefs, work, and fertility. Am Econ J-macroecon. 2009; 1(1): 146-77. Publisher Full Text

30. Caldwell JC, Caldwell P: The cultural context of high fertility in sub-Saharan Africa. Population and development review. 1987; 13(3): 409-437. Publisher Full Text

31. Chang M: Womb for rent: India's commercial surrogacy. Harvard International Review. 2009; 31(1): 11. Reference Source

32. Twine FW: Outsourcing the womb: Race, class and gestational surrogacy in a global market. Routledge. 2015; 118. Publisher Full Text

33. Alabi O: Surrogacy Transcript. figshare. Dataset. 2019. http://www.doi.org/10.6084/m9.figshare.11120891.v1

34. Alabi O: Interview schedule. figshare. Dataset. 2019. http://www.doi.org/10.6084/m9.figshare.10264904.v1

35. United Nations Special Rapporteur: On the sale of and sexual exploitation of children, including child prostitution, pornography, and other sexual abuse material. 2018 .

Reference Source 


\section{Open Peer Review}

\section{Current Peer Review Status: ? ? ?}

\section{Version 2}

Reviewer Report 03 December 2020

https://doi.org/10.5256/f1000research.29719.r75103

(C) 2020 Fawole 0. This is an open access peer review report distributed under the terms of the Creative Commons Attribution License, which permits unrestricted use, distribution, and reproduction in any medium, provided the original work is properly cited.

\section{Olufemi A. Fawole \\ Department of Sociology, University of Ilorin, Ilorin, Nigeria}

The article seems to concentrate more on a particular social group or ethnic group - Yoruba people than on the entire country of Nigeria. Perhaps this will effect a modification of the title of the paper to suit this. Therefore, the topic could be "Perceptions of Surrogacy Within the SocioCultural Context of Yoruba People in Nigeria" or Perceptions of Surrogacy among the Yoruba People of Nigeria". The emphasis is on the Yoruba People as these form the basis of the study. The before are simply suggestions to guide the author on the formation of the topic, and need not necessarily be attended to strictly.

The author may wish to make a comparison between the three major ethnic groups - Yoruba, Hausa and Igbo. But only if it will not be out of the focus of the paper. The author could also attempt to have a look at surrogacy among the cultural group in pre and post colonial times. Having a look at surrogacy in traditional times versus contemporary reasoning could make an interesting contribution to the paper..

The paper concentrated on Ekiti State. The question "Why?" now comes to mind. It is well known that the Yorubas cover the entire South-Western part of Nigeria. What then has become of the core areas such as Oyo and Osun states? Unless the title would now be further limited to "....among the Ekiti People of Nigeria. This will justify why the author is focusing on that region alone. This might be a bit problematic, but could the author identify a few of some of such people who have attempted surrogacy and interview them? Having data from those who actually practiced surrogacy would also help in adding to current literature.

Under "Discussion", 2nd paragraph, line 7, the author stated: "Another stigma associated with infertility is that women having challenges conceiving are believed to have been promiscuous and reckless in their youth..." Was this the perception of those interviewed, or the actual report of such women? this is why having data from women who have practiced surrogacy would go a long way in this study.

The same issue arises here - "because it is evident from the narratives shared by participants that 
when issues of infertility are discussed, women often occupy the centre of the discussion and very little is discussed regarding male infertility." (Same paragraph, lines 9 \& 10. Having those "narratives" from the women involved would make the study more profound.

Another question that comes to mind, is surrogacy seen as an alternative practice to having a child, or a "way out" of the problem of childlessness? To what extent are the people embracing surrogacy as either an alternative method of child bearing or a solution to childlessness? It is possible that some have seen the practice as an alternative, to save them the "troubles" of child bearing.

The author could try these references, to see if they will help:

Ajayi, A. B \& Ajayi, V. (2018) Gestational Surrogacy in Nigeria.

Adelakun, O. S. (2019) The concept of surrogacy in Nigeria: Issues, prospects and challenges.

Author should work on their references to ensure they are complete.

Is the work clearly and accurately presented and does it cite the current literature? No

Is the study design appropriate and is the work technically sound?

Yes

Are sufficient details of methods and analysis provided to allow replication by others? Yes

If applicable, is the statistical analysis and its interpretation appropriate? Not applicable

Are all the source data underlying the results available to ensure full reproducibility? Yes

Are the conclusions drawn adequately supported by the results? No

Competing Interests: No competing interests were disclosed.

Reviewer Expertise: Marriage and the Family

I confirm that I have read this submission and believe that I have an appropriate level of expertise to confirm that it is of an acceptable scientific standard, however I have significant reservations, as outlined above.

Author Response 26 Jan 2021

Oluwatobi Alabi, University of Johannesburg, Johannesburg, South Africa 
Thank you very much for the very constructive recommendations. Most of your recommendations have been put into consideration as you will see in the most recent version of this article.

Moreover, I will like to highlight the following to provide context and clarification. The aim of the study was simply to present the contemporary perception of surrogacy within the socio-cultural context of this location. While the review of scholarly literatures presented was intended to give context to the study and highlight the reasons why it has become important to critically examine reasons why surrogacy might not be a popular reproduction option in Nigeria. As an empirical investigation, it is also very important to stay within focus because of the purpose and the limitation of time and resources. For emphasis and in line with the guideline of a qualitative design, it is important to stay within reasonable context since the purpose of the study is not to generalize but provide indepth knowledge of a specific problem within a certain context. The aim of this study is to understand the sociocultural context of surrogacy within Ado-Ekiti and the topic has been further clarified.

The narratives discussed emanated from the responses of participants and the categories of participants in this study have been clearly explained. The study in some instances also indicated that reasons to why surrogates and their clients have become a 'hard to reach population' in Nigeria and this is closely related to the social stigma accompanying medical reproductive options. Clarifications have been made all through the article to ensure that surrogacy is discussed not as an option to reproduction but as one of the medical alternatives to treating infertility or rather a reproduction process.

Thank you again and I sincerely hope you enjoy reading the latest version of this article.

Competing Interests: No competing interests were disclosed.

\section{Version 1}

Reviewer Report 07 April 2020

https://doi.org/10.5256/f1000research.23108.r60862

(c) 2020 Mbara G. This is an open access peer review report distributed under the terms of the Creative Commons Attribution License, which permits unrestricted use, distribution, and reproduction in any medium, provided the original work is properly cited.

\section{George Mbara}

Discipline of Criminology and Forensic Studies, University of KwaZulu Natal, Durban, South Africa

The article presents surrogacy as an aspect of assisted reproductive technology (ART) and explores the challenges inhibiting the acceptance of the practice among Nigerians. The study collected its data from a particular region of the country (South West) and thus, makes 
generalisations on the findings. Most of the respondents were collected from one ethnic group (the Yorubas) and mostly professional gynaecologists. The findings of the study were erroneously generalised as representing the entire country.

Nigeria is not a homogeneous country as presented in the title of this investigation. The country has over two hundred and fifty (250) ethnic nationalities domiciled within its borders ${ }^{1}$. This diversity transcends religion, culture and socio-political inclinations. Years before the 15th century, most of the ethnic groups that make up present-day Nigeria can all trace their origins to different states. Among the early states were the Benin Kingdom, the Yoruba Kingdoms, Hausa States, Nupe, and the Igbo-ukwu. Countless small states existed around the Lake Chad region which was later swallowed or dispersed during the expansion of Kanem to the North East of Lake Chad (Mbara, 2018:12). Historically, these groups were differentiated based on their socio-political organization. The Yorubas, Hausas and the Binis had a centralized administrative system while the Igbos of the East have variously been described as a "stateless" society because unlike the Hausa, Yoruba and Benin Kingdoms, they did not have a central political institution. Further, the indigenous people that inhabited the country today were profoundly divided by their historical experiences, culture, political development, and religion.

Thus, a topic like this should look at surrogacy based on the teachings and practices of a particular culture or religion. Investigating surrogacy in 'Nigeria' as a whole makes the study problematic given the fact that the three major tribes (Igbo, Yoruba and Hausa), for instance, have very diversified cultural and even religious beliefs/inclinations which deeply impact their social existence. The author alludes to this when he declared, "What surrogacy means and the social reception it enjoys differ across cultural and social boundaries" (p.5). For this reason, this study will best suit a particular ethnic nationality or religion in Nigeria. Just as their ethnicity and religion differ, so to their belief systems are very divergent. The influence of Western education on these ethnic nationalities intensified this division among the people leaving some very conservative (the North) and others more progressive (the South) at varying degrees. This makes surrogacy a very contentious and subjective issue.

Consequently, the best title for this work should be "A qualitative investigation of surrogacy as a panacea for infertility among the Yoruba people of Nigeria" given the setting of the interviews coupled with the fact that "The interview schedule was translated into Yoruba, the local language of this Western region of Nigeria for the benefit of the TBAs who might not be English speakers" (p.4). With the vast size of Nigeria and the heterogeneous nature of the country, getting most of your sample population from Ekiti State will surely not give you enough grounds to caption the findings as Nigeria. Buttressing this view, Alabi (2020:5) in his results submits, "The dynamic nature of human societies coupled with varying regulatory normative codes across cultural boundaries creates the need to examine the perception of surrogacy within various cultural settings to appreciate the differences and similarities that are obtainable in the growth of the practice as a core ART process". Thus, he cannot lump over 250 ethnic nationalities in Nigeria and discuss them as a single culture. A little search will reveal that surrogacy has been in practice in many Nigerian societies and in different forms.

Furthermore, for a more holistic view of the subject matter of this investigation, the stakeholders for the interview should have included a Christian, a Muslim and an adherent of the African Traditional Religion (ATR). This is because Nigerians are a deeply religious people and their religion impacts their culture, lifestyles and value systems. Likewise, some custodians of culture 
like traditional rulers from the major ethnic groups should also constitute the stakeholders. However, the problem of ethnic minorities and the fear of domination will make it more difficult to select the cultural groups that will participate in the investigation. Thereby justifying the need to narrow down the investigation to an ethnic/religious group in the country. If the investigation is done based on the above recommendation, the author will find very diversified views on the subject matter in Nigeria.

Surrogacy, as presented in this text (ART or fertility treatment), is quite alien to most Nigerian cultures and so, the scholar presents it as a taboo in the country as evidenced in his findings. In the first place, ART is the medical procedures used in treating the problem of infertility. Such procedures include, in vitro fertilization, cryopreservation of gametes or embryos, intracytoplasmic sperm injection, among others. I align my thoughts with the first reviewer who declared, "Surrogacy is not an ART nor a 'fertility treatment' (p. 3), as the insemination in some countries is also achieved with coitus (there are documented cases in Mexico and China)" (Danna, 2020:10). The relationship between surrogacy as an ART as presented in the text is shrouded in ambiguities thus leaving room for multiple interpretations. Surrogacy (renting a womb, see pages $7 \& 8$ ) has been in practice in different forms in many Nigerian cultures. In some cases, the problem of infertility is solved by the man consenting to a family member impregnating his wife on his behalf. The "sperm donor" lays no claim to the child. The impotent man plays the father figure to the child who bears his name. In other cases, it was the barren wife in a marriage that took a younger wife for herself. Correspondingly, when a man dies childless, a family member can sleep with the woman (his wife) to produce an heir for the deceased (See the Igbos of Eastern Nigeria, the Ibibios of South-south Nigeria). In these cultures, these practices are often altruistic in nature.

In particular, among the Igbos of Eastern Nigeria, surrogacy has been in practice in various forms like the woman-woman marriage. Commenting on this practice, Aliyu (2018: para 3) maintains: In these various societies, the wives other women married were ladies-in-waiting, surrogate mothers, and daughters-in-law... Woman-to-woman marriage allowed for greater freedom of sexuality for the wives, they could have boyfriends, anonymous men whose only duty was to supply sperm, Achebe calls them "male sperm donors", and this was socially accepted. Any child the wives had was taken care of by their female husband and carried her name, and this was legitimate in the eyes of society.

Woman-to-woman marriage practice did not include any sexual contact between the female husband and her wife. This was not "lesbianism," since none of the women who married other women was drawn to other women either romantically or sexually. Children were the prime attraction, every woman who turned into a female husband only wanted a child considered legitimate in the eyes of society. In the same vein, Nwoko (2012) gives other examples of surrogacy among the Mbaise Igbo where a family's female children jointly paid the pride price of a younger lady after the death of their father in the name of their eldest sister, so that the new bride could procreate and raise male children to maintain the lineage of the family. Essentially, a wellbehaved young man was chosen by the young bride from the kindred, but in most cases, the bedmate was chosen from the female husband's blood relationship. This had significant implications as it was aimed at maintaining the blood tie of that particular family and to prevent the young bride from polluting the family by raising children fathered by persons with strange ailments, thieves or miscreants. 
To actualize the essence of the marriage, Nwoko (2012:76) adds:

The female husband remained the sociological father of any resulting offspring. The children belonged to the lineage of her father, not to their biological father. Consequently, she played the role of the father, provider, protector and indeed all the functions and responsibilities enshrined in the patriarchal concept which included physical protection of the family and its territory, the male economic sphere, the spiritual sphere, the social sphere, etc.

Surrogacy in the context of 'renting' a womb is still a cultural anomaly in most Nigerian cultures, but as an altruistic act, it has been around over the years.

Moreover, how can surrogacy be a panacea for infertility in Nigeria? The simple meaning of panacea is "cure-all". Surrogacy can be an option, not a panacea since there are multiple factors responsible for infertility, some are more complex than others. Various traditional treatments are available to infertile couples in Nigeria. Thus, surrogacy cannot be a panacea as the author implies.

Additionally, in the abstract, 15 stakeholders were stated by the author as respondents, but in the methodology, 10 gynaecologists, 5 TBAs and 5 Legal professionals making a total of 20 respondents. Please reconcile the numbers and justify the sample size especially the 10 gynaecologists. This investigation is more of a social phenomenon than medical and should have covered custodians of some traditions/cultures. Gynaecologists can provide us with some scientific aspects of fertility treatment but not surrogacy as a cultural practice. Why were social workers not interviewed?

Besides, in the data collection under methodology, the scholar declares, "The first set of questions examined surrogacy within a cultural perspective" (p.4). Who provided this information? In my opinion, the traditional rulers or elders of various cultural groups should be in the best position to provide the necessary information here. They are the custodians of the various cultures, not the TBAs. If due diligence was carried out here, the findings would have been remarkably different from what we have here.

'Interviews lasted on average of 30 minutes.' Unnecessary repetitions.

Moreover, in p.5, the author states, 'The opinions shared by TBAs were grounded in religious and cultural beliefs, leading to opposition to its practice". This response was perhaps predicated on the false assumption that surrogacy is an "alternative to infertility". Besides, one can ask, what religion and what culture in Nigeria? This gives room for ambiguities and subjective interpretations. Even when it comes to religions like Christianity in Nigeria, some sects/denominations hold more radical or conservative approach to issues surrounding modern-day surrogacy (Renting a womb with pecuniary incentives). For example, the Catholics and Jehovah Witnesses will surely diverge in their views. The same applies to the Deeper lifers (radicals) and say a Baptist Christian (conservatives). Even in ATRs, the various cultures will have varying degrees of acceptance or abhorrence for surrogacy. There are also individuals in Nigeria who, as a result of Westernisation, have accepted this practice. So many young couples in Nigeria now see surrogacy as a viable option for procreation.

In p.6, the scholar declares, "However, infertility is regarded most times as a woman's problem and evidence of sin and disapproval by both God and ancestors". The influence of Christianity (Catholicism in particular) is fast changing this view among some Nigerian Catholics as Canon 1084.3 clearly states that sterility does not forbid nor invalidate a marriage (when there has been no form of deceit). A childless marriage is valid, and companionship is equally very important in marriages. In preparatory classes, intending couples are exposed to this reality. While a childless 
couple keeps seeking a remedy to their condition, they are made to understand that it does not invalidate/nullify their union. For this reason, a marriage contracted under the church cannot be dissolved for the reason of childlessness. This explains why you find pockets of couples who have been in the union for decades despite been childless. This does not, however, negate the fact that fertility is still a very integral part of the people/lay faithful.

This investigation should look at surrogacy as a "viable" option in the case of infertility instead of a 'panacea' since it is an exploratory study which discovered that the practice is still very alien to the people and unacceptable. The title as it is gives the impression that surrogacy was discovered to be the 'solution' instead of an 'alternative'. If I am right, the author seeks to sell the idea of surrogacy as a viable option in the case of infertility, not a total solution. The word 'panacea' denies other viable options available like IVF, adoption, polygamy or cases where a relative impregnating the wife of an impotent brother to preserve the bloodline, or where a woman marries another woman with the sole purpose of procreation.

The study pointed out the factors militating against the adoption of surrogacy as a panacea to infertility in Nigeria but failed to establish the need for surrogacy in the country thereby making the title a misnomer. To declare surrogacy a panacea requires that other alternatives were investigated and found wanting, thus necessitating the adoption of surrogacy as a "cure-all" remedy.

Consider women who give birth through a caesarean section? Some Africans (Nigerians) still do not see them as complete women since they have not felt the pangs of birth.

Lastly, some typographical/grammatical errors were observed in the work - articles were either omitted or wrongly used. For example, subheading (p. 7): "Surrogacy reorganizing the essence of parenthood in Nigeria" (Add colon or dash after 'Surrogacy'), "While surrogacy might be glorious news..." (p.7. rework), "and it often seen" (p.3. Rework).

\section{References}

1. Nigeria Fact Sheet. United States Embassy in Nigeria. 2019; 22 (4). Reference Source

2. Aliyu R: Woman-woman marriage in Pre-Colonial Igboland. The Rustin Times. 2018. Reference Source

3. Ononihu SC, Oddih MC: Nigeria's Quest For A Permanent Seat At The United NationsSecurity Council: An Appraisal. IOSR Journal Of Humanities And Social Science. 2017; 22 (4). Reference Source 4. Nwoko KC: Husbands in Igbo Land: Southeast Nigeria. The Journal of Pan African Studies. 2012; 5.

\section{Is the work clearly and accurately presented and does it cite the current literature?} No

Is the study design appropriate and is the work technically sound? Yes

Are sufficient details of methods and analysis provided to allow replication by others? Yes

If applicable, is the statistical analysis and its interpretation appropriate? Not applicable 


\section{Are all the source data underlying the results available to ensure full reproducibility?} Yes

\section{Are the conclusions drawn adequately supported by the results?} No

Competing Interests: No competing interests were disclosed.

Reviewer Expertise: Political Science, International relations, cyber security, security studies, African philosophy and ethics, public governance and climate change.

I confirm that I have read this submission and believe that I have an appropriate level of expertise to confirm that it is of an acceptable scientific standard, however I have significant reservations, as outlined above.

\section{Author Response 17 Sep 2020}

Oluwatobi Alabi, University of Johannesburg, Johannesburg, South Africa

Hi George,

Thank you for your very insightful comments on this article. I find them very useful for the review and the recommendations in most of the case helped in the production of the new version.

However, unlike you implied in some instances, the article never assumed to generalize its findings to the entire Nigeria and in no instance was Nigeria as a country presented as the study location. While the topic might have Nigeria named which was a mix up during the editorial process with the journal, the methodology gives the reader a detailed description of the specific study location in Nigeria. Likewise, as a qualitative study, it aim was not to generalize findings but provide a more detailed understanding of surrogacy within the study location.

Also, the article does not intend or aim to make a case for/against the practice of surrogacy in Nigeria. Rather, it seeks to investigate how various socio-cultural and religious factors influencing reproduction in Nigeria and south-west Nigeria in particular shape the perception of surrogacy within the studied population.

Thank you again for your insightful comments.

Competing Interests: No competing interests were disclosed. 
(c) 2020 Danna D. This is an open access peer review report distributed under the terms of the Creative Commons Attribution License, which permits unrestricted use, distribution, and reproduction in any medium, provided the original work is properly cited.

\section{Daniela Danna}

Department of Social and Political Science, University of Milan, Milan, Italy

The proposed article is based on personal interviews with professionals in health and law on the subject of surrogacy. The author takes a clear stand for "modernization", where he considers surrogacy an ART. He presents in a favorable light the positive attitudes towards surrogacy by legal experts and gynecologists (mostly male) and in a negative light the objections expressed by traditional birth attendants (all female).

The objective of the article is to identify cultural obstacles to the normalization of this practice, as the author considers it a panacea for infertility, therefore positive, progressive, good.

There are multiple problems with his view, the principal one is the blurring of what happens in surrogacy and the imprecision in its description, that is missing its concrete aspects. (This blurring is surprising, considering that my own contribution Contract children, a book exactly describing at the global level the phenomenon and its legal and ethical requisites, is listed in the bibliography. I have since published another article that might be of help to the author: "The subrogation of motherhood: a juridical institution putting kinship on the market", in Salute e società, n. 2, 2019, pp. 44-59 ${ }^{1}$ ). Instead of providing a description, the author defines surrogacy as an ART or an "alternative to infertility" (p. 5), and the whole paper rests on this faulty premise.

Surrogacy is not an ART nor a "fertility treatment" (p. 3), as the insemination in some countries is also achieved with coitus (there are documented cases in Mexico and China). It is instead the motherhood of a woman that will not be considered the legal mother - by deception of the authorities or by changes in the filiation laws. It is essentially a third way to become legal parents besides birthing (with or without recognition by the natural father, a recognition that happens automatically when the mother is married) and adoption. Therefore juridical language should be employed, as it is a juridical institution: the subrogation of motherhood. But out of simplicity I will also call this practice "surrogacy".

The mother, that is - in objective language - the woman who has given birth, renounces by contract to her right to the baby (called in law the principle of mater semper certa) in exchange for money, often called "reimbursement". Where are those "cases of altruism" that the author claims to stand on a par with the commercial version (p. 5)?

Illegal surrogacy happens, and it is just a practice where the delivery of the baby to third persons is achieved by payment or by illegal force, but when it is regulated by law - despite usually taking place in clinics - is not at all a medical practice, but a pregnancy not essentially different from other pregnancies. The IVF can or cannot take place, and the insemination can happen outside clinics. The fact that surrogacy is clinically managed does not pertain to the core of the practice, which is the legal possibility to sell filiation by the mother to the prospective, and paying, parent(s).

It is therefore wrong to state in the abstract that, before surrogacy, adoption was "the most common alternative" to legally become a mother, as adoption was the only alternative to birthing 
a child.

The major problem with the aseptic definition of surrogacy as an ART - that is, as if it were technology - is that this definition takes for granted that the woman who gives birth will renounce her baby, will renounce her right to legally recognize her baby. But this is not inherent in the practice, which is merely based on a promise. The certainty will only come with legally binding documents: a contract that is currently invalid in most countries. She will surely give up the baby only if she is bound by a contract that is deemed legally valid - for this reason is surrogacy a juridical institution. This use of a woman's body to obtain a son or daughter - I repeat - is in nearly all cases paid for, and the Rapporteur for the U.N. on child trafficking has already declared commercial surrogacy to be trafficking in babies, and - in her last contribution on the subject that I have read - awaited for supporters of "altruistic" surrogacy to demonstrate that such a thing really exist and is not merely a label for the same selling of commissioned newborns. The author apparently ignores the Rapporteur's conclusion that commercial surrogacy is a violation of the human rights of the newborn, it is an indignity suffered by a mother, and becomes a violation of her human rights, too, when she changes her mind having developed a motherly relationship with her baby but cannot keep him or her because she signed a contract more than nine months before.

But how can the author ask others about "how surrogacy is conceptualized in Nigeria" while he has a superficial concept of surrogacy as (just) an ART? Why does he cancel out the legal debate, and does not give the reader the fundamental information of how surrogacy is legally defined in Nigeria? And if it does not appear in law (as far as I know this is the case), what are the consequences for people who may have done informal agreements? Have there ever been real cases? There are sources on forcing pregnancy on women already trafficked for the purpose of prostitution - should this not be discussed?

How can he claim that gynecologists have a "more informed opinion" on surrogacy (p. 5) when his own description of it is blurry and essentially wrong? Other questions that come to my mind pertain to the framing of the interviews that he conducted: Do not gynecologist talk from their own cultural point of view, like the TBAs? What is "scientific" about their opinions on surrogacy? It seems to me that the TBAs are closer to target (see end of the review).

In general, the interview material could be analysed in more depth and with more quotations. The author's denomination of "modern" for surrogacy is hardly accurate, as it is well know that there are descriptions in the Bible. The author is worried about stigma creation, but what if surrogacy in itself is violence? Violence against the newborn, who is not a tabula rasa but needs his or her mother, and actively looks for her for the nourishment from her breasts? Violence against the numerous women who do not want to give up their babies after birth but are forced to do it by monetary penalties or even by the force of the State (see the cases of Baby M and Melissa Cook, among many others)? Should acts of violence be free from "stigma"? Should not surrogacy be correctly nominated for what it is: an unnecessary separation of the dyad mother-newborn because intermediaries (and doctors and legal experts, as we see in other countries) profit from the plight of infertile couples, suggesting and organizing this trafficking for their own profit? It seems to me that the explanation for the favorable opinions of doctors and legal experts that the author has found, could be grounded in their own prospect of becoming part of these agreements, organize them and profit from them.

There is a class dimension and an inequality basis in surrogacy that are totally foregone in the 
proposed article: there is no altruistic surrogacy but women in need that accept to become pregnant and give up their babies to richer couples/singles because they are paid. (Of course there is the question of consciousness, of subjectivity: many women who get paid say that this is not their primary goal, but without money they most certainly would not undergo a pregnancy for others.)

Therefore there is no "purely altruistic" commitment (very few exceptions apart) as ALL the legislations canceling mater semper certa allow for "reimbursements" that can be conspicuous. Without money, there would be no surrogacy of relevance, just a few cases now and then. But the aim of the author - whether he realizes it or not - is to set up a market for newborns by obscuring what is really taking place in the countries that have introduced surrogacy.

Another problem with the general framework of the paper is that, even though the author laments the identification of "woman" with "mother", he basically suggests a method for a woman to become (by means of paying another woman) a mother even if the couple is infertile. Then we are back to square one with the identification woman=mother. A true alternative would be a change in culture that, instead of working for the social acceptance and normalization of rich couples paying poor women for their babies, would work for the social acceptance of women who cannot, or do not want, to become mothers.

I am no native English speaker, so I cannot judge the overall quality of the language, but I noted that there is sometimes a lack of grammatical concordances between verb and subject, and there might be other errors (as in my own text). I do not understand for example "data saturation". Other minor points: at p. 3 what is "holistic" in ART procedures, that is the artificialization of reproduction, that result in babies being born with more health problems than naturally conceived babies? What is a "foundational and an experimental level" (same page)? Why is infertility considered a particular case of "sickness" (same page), when the organism that is infertile is in fact generally healthy? What is a "visual text" (p. 4)? Should "corporate" at p. 6 not be "cooperate" (interesting slip of the tongue, as the article advocates for a new market in newborns)?

Finally: at p. 8: surrogacy is not "one of the most progressive ways of addressing infertility", nor "a desirable fertility alternative", but buying and selling newborns exploiting the poor women that are forced by need to take up pregnancy as a job (even in the US they sign surrogacy contracts for such goals as paying for the tuitions of their other children). The TBAs might express this and the refusal of such a market in the language of religion, but they are closer to reality than the various experts who stand to gain from the introduction of this juridical institution.

\section{References}

1. Danna D: The subrogation of motherhood: A judicial institution that puts kinship on the market. SALUTE E SOCIETÀ. 2019. 44-59 Publisher Full Text

\section{Is the work clearly and accurately presented and does it cite the current literature?} No

Is the study design appropriate and is the work technically sound? Yes

Are sufficient details of methods and analysis provided to allow replication by others? 
Yes

If applicable, is the statistical analysis and its interpretation appropriate?

Not applicable

Are all the source data underlying the results available to ensure full reproducibility? Yes

Are the conclusions drawn adequately supported by the results?

No

Competing Interests: No competing interests were disclosed.

I confirm that I have read this submission and believe that I have an appropriate level of expertise to confirm that it is of an acceptable scientific standard, however I have significant reservations, as outlined above.

Author Response 17 Sep 2020

Oluwatobi Alabi, University of Johannesburg, Johannesburg, South Africa

Hi Daniela,

Thank you for your very insightful comments on this article. I find them very useful for the review and the recommendations in most of the case helped in production of the new version. However, I will like to state emphatically that I stand to benefit nothing from the commercialization of surrogacy in Nigeria like you implied in some instance.

In fact, the article does not intend or aim to make a case for/against the practice of surrogacy in Nigeria. Rather, it seeks to investigate how various socio-cultural and religious factors influencing reproduction in Nigeria and south-west Nigeria in particular shape the perception of surrogacy within the studied population.

Thank you again for your insightful comments.

Competing Interests: No competing interests were disclosed. 
The benefits of publishing with F1000Research:

- Your article is published within days, with no editorial bias

- You can publish traditional articles, null/negative results, case reports, data notes and more

- The peer review process is transparent and collaborative

- Your article is indexed in PubMed after passing peer review

- Dedicated customer support at every stage

For pre-submission enquiries, contact research@f1000.com 